\title{
One year outcome in mild to moderate head injury: the predictive value of acute injury characteristics related to complaints and return to work
}

\author{
J van der Naalt, A H van Zomeren, W J Sluiter, J M Minderhoud
}

\begin{abstract}
Objectives-To determine the prognostic value of characteristics of acute injury and duration of post-traumatic amnesia (PTA) for long term outcome in patients with mild to moderate head injury in terms of complaints and return to work. Methods-Patients with a Glasgow coma score (GCS) on admission of 9-14 were included. Post-traumatic amnesia was assessed prospectively. Follow up was performed at $1,3,6$, and 12 months after injury. Outcome was determined by the Glasgow outcome scale (GOS) 1 year after injury and compared with a more detailed outcome scale (DOS) comprising cognitive and neurobehavioural aspects.

Results-Sixty seven patients were included, mean age 33.2 (SD 14.7) years and mean PTA 7.8 (SD 7.3) days. One year after injury, $73 \%$ of patients had resumed previous work although most (84\%) still reported complaints. The most frequent complaints were headache $(32 \%)$, irritability (34\%), forgetfulness and poor concentration (42\%), and fatigue (45\%). According to the GOS good recovery $(82 \%)$ or moderate disability $(18 \%)$ was seen. Application of the DOS showed more cognitive $(40 \%)$ and behavioural problems $(48 \%)$, interfering with return to work. Correlation between the GOS and DOS was high $(r=0.87, \mathrm{p}<0.01)$. Outcome correlated with duration of PTA $(r=-0.46)$ but not significantly with GCS on admission $(r=0.19)$. In multiple regression analysis, PTA and the number of complaints 3 months after injury explained $49 \%$ of variance on outcome as assessed with the GOS, and $60 \%$ with the DOS.

Conclusions-In mild to moderate head injury outcome is determined by duration of PTA and not by GCS on admission. Most patients return to work despite having complaints. The application of a more detailed outcome scale will increase accuracy in predicting outcome in this category of patients with head injury. (F Neurol Neurosurg Psychiatry 1999;66:207-213)
\end{abstract}

Keywords: head injury; post-traumatic amnesia; outcome

Dr J van der Naalt,

Department of Neurology,

University Hospital

Groningen, PO Box 30.001,

9700 RB Groningen, The

Netherlands. Fax 003150

3611707; email

j.van.der.naalt@neuro.azg.nl

Received 30 December 1997 and in revised form 22 June 1998

Accepted 9 July 1998 documented outcome of patients with severe head injury. Patients with persistent symptoms have long been regarded as malingerers ${ }^{56}$ with vague complaints and minor neuropsychological disturbances. Other authors have stressed the hypothesis that even mild brain concussions cause (reversible) lesions and that complaints should be regarded as starting from a physical base. ${ }^{7-9}$ Since axonal injury has been recognised as a consistent feature of various grades of brain injury in animals ${ }^{10-12}$ and humans, ${ }^{13-15}$ persisting symptoms and signs in mild to moderate head injury have been acknowledged as deserving more attention.

Several problems arise when evaluating the outcome of this group of patients. Firstly, the lack of a consistent definition of mild and moderate head injury. ${ }^{16}{ }^{17}$ In early studies, the duration of PTA was used to define patients ${ }^{18}$ while currently the GCS is used to do this. Patients with a GCS of 9-12 are regarded as having moderate head injury whereas patients with a GCS of 13-15 are regarded as having mild injury. In several studies however, additional criteria such as CT abnormalities and admission to hospital for less than 48 hours are used to exclude patients with more severe mild injuries. On the other hand, patients with a GCS of 15 are regarded as having minor head injuries with less severe outcome compared with patients with mild and moderate head injury. Secondly, in the literature, outcome is often determined only once at 3 to 6 months after injury and follow up at regular intervals beyond that period is missing. Thirdly, it is recognised that the commonly used outcome scales are not suitable for measuring the outcome in mild to moderate head injury as they assess functional disability more than cognitive deficits. ${ }^{19} \mathrm{Al}-$ though neuropsychological impairment demonstrated at baseline usually resolves within 3 months ${ }^{2021}$ patients may still have selective deficits in attention and memory. ${ }^{22}{ }^{23}$ Finally, by contrast with severe head injury no agreement has been reached on the predictive value of the acute injury characteristics such as the GCS score and the duration of PTA on outcome. ${ }^{24}$

The purpose of this study was to describe the long term outcome of patients with mild to moderate head injury with a GCS of 9-14 irrespective of duration of stay in hospital or CT abnormalities. Complaints and return to work were analysed, with follow up at regular intervals. In addition, the assessment of outcome as determined by the GOS was compared with a more detailed outcome scale. Furthermore, it was investigated whether the GCS score on admission and duration of posttraumatic amnesia (PTA) can predict the outcome in this category of patients. 
Patients and methods

Patients eligible for the study had to satisfy the following inclusion criteria: age between 15 and 65 years, GCS on admission between 9-14 and duration of PTA of at least 1 hour. Exclusion criteria were: history of previous admission to hospital for head injury, addiction to alcohol or drugs, known psychiatric disorder or mental retardation, and severe aphasia obstructing the assessment of the PTA. Patients with a PTA for more than 28 days were excluded. Mild head injury was defined by a GCS on admission of 13-14 and moderate head injury was defined by a GCS on admission of 9-12.

MEASUREMENT OF GCS AND PTA

In general, patients were admitted directly to the hospital within 1-2 hours after injury. The GCS at admission was assessed as part of the neurological examination. Registration of the PTA was started as soon as patients had regained consciousness and were able to communicate (with a verbal score of 4 on the GCS), by means of a questionnaire adapted for use by nursing staff (appendix 1). All 12 items in the PTA questionnaire have been validated clinically - that is, all items differentiated between patients in hospital with and without head injury. Twice daily the degree of PTA was determined by testing orientation and memory, with a range of score from 0 to 12 points. Once the maximum score of 12 was obtained, the patient was regarded as out of PTA which by definition is equal to the period from injury to the moment when the patient has continous memory for ongoing events. ${ }^{18}$

FOLLOW UP

After discharge from the hospital follow up was done at regular intervals: at $1,3,6$, and 12 months after injury. During each visit a checklist of complaints was filled out together with a structured interview and a neurological examination.

Symptom checklist

The symptom checklist contains 19 symptoms that are often reported in the literature as part of the sequelae of traumatic head injury. This symptom checklist is comparable with the head injury symptom checklist (HISC) ${ }^{25}$ with addition of symptoms concerning arm pain and neck pain and some complaints not relevant for concussion. The last items were meant to check for a strong tendency to complain. To control for the base rates of complaints in the general population, subjects were also asked if they experienced any of the complaints before the injury, and if they did, whether these had stayed the same or had worsened since the injury. They also were asked whether they were presently experiencing symptoms, and if they did, to qualify them as occuring seldom (score 1 ) or often (score 2). In this manner the total number of complaints and the severity of symptoms expressed by the frequency of occurrence were recorded.

Outcome scores

At 1 year after injury the outcome was determined by the original $\mathrm{GOS}^{26}$ and the extended GOS comprising eight outcome categories. ${ }^{27}$ The extended GOS contains the following categories: (original GOS codes given in parentheses for comparison) score $8=$ good recovery (5); score $7=$ good recovery with minor physical or mental deficits (5); score $6=$ moderate disability, return to previous work with some adjustments (4); score 5=moderate disability, work at a lower level of performance (4); score $4=$ severe disability, for some activities dependent on others (3); score $3=$ severe disability, completely dependent on others (3); score $2=$ vegetative state (2); score $1=$ death (1).

The use of the extended GOS with eight categories (GOS-8) has been recommended because patients with a mild or moderate head injury in general end up with a good recovery or moderate disability and this scale describes this upper range of outcome more in detail. In a further attempt to assess the outcome in more detail, a third and even more extended outcome scale (DOS) has been devised that specifies outcome in four subscales on social, behavioural, cognitive, and physical sequelae (appendix 2). In each category of outcome a five point scale is applied. The lowest total score attainable is four points for a persistent vegetative state and the highest total score is 20 points for complete recovery. The DOS has two advantages: the scale is more finely divided than the GOS and the four digit code gives specific information concerning remaining impairments. The outcome was assessed twice by the treating neurologist (JvdN) and independently by a second neurologist (JMM) without knowledge of the history of the patient. This double scoring of the 1 year outcome was arranged to study the interobserver variability of both outcome scales, the GOS- 8 and the DOS.

Return to work

Resumption of work or previous activities was scored 1 year after injury. This scoring comprises 4 categories: $0=$ previous work or study resumed; $1=$ previous work or study resumed;

Table 1 Prevalence of complaints during follow up represented in percentages of patients with complaints for the total study population

\begin{tabular}{lrrrr}
\hline Complaint & 1 month & 3 months & 6 months & 1 year \\
\hline Headache & 37 & 26 & 19 & $32^{\star}$ \\
Dizziness & $59^{\star}$ & $42^{\star}$ & $33^{\star}$ & 25 \\
Balance disorders & 29 & 16 & 13 & 14 \\
'Tinnitus' & 29 & 21 & 17 & 20 \\
Hearing loss & 18 & 10 & 14 & 12 \\
Drowsiness & $55^{\star}$ & $58^{\star}$ & $48^{\star}$ & $42^{\star}$ \\
Fatigue & $57^{\star}$ & $61^{\star}$ & $45^{\star}$ & $45^{\star}$ \\
Forgetfulness & $53^{\star}$ & $44^{\star}$ & $38^{\star}$ & $42^{\star}$ \\
Poor concentration & $51^{\star}$ & $44^{\star}$ & $44^{\star}$ & $42^{\star}$ \\
Slowness & 39 & 29 & 25 & 25 \\
Irritability & 35 & 27 & $26^{\star}$ & $34^{\star}$ \\
Noise intolerance & $53^{\star}$ & $40^{\star}$ & 25 & 28 \\
Alcohol intolerance & 6 & 11 & 17 & 20 \\
Anxiety & 20 & 19 & 19 & 26 \\
Dry mouth & 17 & 15 & 6 & 9 \\
Neck pain & 27 & 21 & 14 & 22 \\
Neck stiffness & 14 & 7 & 3 & 9 \\
Arm pain & 22 & 24 & 16 & 17 \\
Itching & 18 & 23 & 16 & 9 \\
No complaints & 4 & 18 & 11 & 14 \\
Complaints & 96 & 82 & 89 & 86 \\
Range & $0-15$ & $0-17$ & $0-16$ & $0-16$ \\
Number (mean) & 6.3 & 5.4 & 4.4 & 4.7 \\
Severity (mean) & 8.0 & 7.0 & 5.5 & 5.7 \\
\hline \& & & & & \\
\hline
\end{tabular}

$\star$ Six most frequent complaints at each follow up period. 
Table 2 Resumption of work or study over time for patients with moderate or mild head injury (HI) (expressed in percentage of patients in each category)

\begin{tabular}{|c|c|c|c|c|c|c|c|}
\hline \multirow[b]{2}{*}{ Injury } & \multirow[b]{2}{*}{$n$} & \multicolumn{4}{|c|}{ Months postinjury } & \multirow{2}{*}{$\begin{array}{l}\text { Interval } \\
\text { injury-RTW } \\
\text { months mean (SD) }\end{array}$} & \multirow{2}{*}{$\begin{array}{l}\text { RTW full } \\
\text { capacity month } \\
\text { mean (SD) }\end{array}$} \\
\hline & & 1 & 3 & 6 & 12 & & \\
\hline Mild HI & 43 & 39 & 67 & 97 & 100 & $2.7(1.8)$ & $5.6(3.6)$ \\
\hline Moderate HI & 23 & 5 & 45 & 90 & 100 & $4.1(2.4)$ & $7.8(5.5)$ \\
\hline All HI & 66 & 27 & 59 & 95 & 100 & $3.2(2.1)$ & $6.2(4.3)$ \\
\hline
\end{tabular}

RTW=Return to work.

Table 3 Outcome 1 year after injury according to the DOS scale related to the outcome determined by the GOS (original (GOS-5) and extended (GOS-8) version (expressed in percentage of patients in each category)

\begin{tabular}{|c|c|c|c|c|c|c|c|c|c|}
\hline \multirow[b]{2}{*}{ DOS scale } & \multirow{2}{*}{$\begin{array}{l}\text { All HI } \\
(n=67)\end{array}$} & \multirow{2}{*}{$\begin{array}{l}\text { Mild HI } \\
(n=43)\end{array}$} & \multirow{2}{*}{$\begin{array}{l}\text { Moderate HI } \\
(n=24)\end{array}$} & \multicolumn{2}{|c|}{ GOS-5 scale } & \multicolumn{4}{|c|}{ GOS-8 scale } \\
\hline & & & & 4 & 5 & 5 & 6 & 7 & 8 \\
\hline Physical problems & 37 & 35 & 42 & 75 & 29 & 100 & 82 & 48 & 0 \\
\hline Social problems & 22 & 14 & 38 & 100 & 5 & 100 & 100 & 9 & 0 \\
\hline Cognitive problems & 40 & 40 & 63 & 83 & 31 & 100 & 82 & 48 & 5 \\
\hline Behavioural problems & 48 & 28 & 63 & 92 & 38 & 100 & 91 & 64 & \\
\hline
\end{tabular}

$\mathrm{HI}=$ Head injury

but with lower demands or part time; $2=$ previous work or study not resumed, different work on a significantly lower level; $3=$ not working.

\section{STATISTICAL ANALYSIS}

All data were analysed with the statistical package for the social sciences (SPSS). Parametric (Student's $t$ test) or non-parametric (MannWhitney $U$ test) tests were used when appropriate. Pearson's correlation coefficients were calculated for relations between all independent measures. Agreement of interobserver scoring was assessed by weighted $\kappa$ analysis. Frequency analysis was performed using $\chi^{2}$ tests, with correction for continuity. Multivariable regression analysis was done by using a stepwise backward method. Distribution of outcome variables was considered sufficiently normal for scales with four or more points, the other outcome variables were entered as categorical variables.

\section{Results}

Seventy patients were included. Three patients (4\%) were lost to follow up, leaving 67 patients for further analysis. The group comprised 43 men and 24 women with a mean age of 33.2 years (SD 14.7, range 15-64 years). The mean

Table 4 Duration of post-traumatic amnesia (PTA) and outcome variables 1 year after injury in different head injury categories

\begin{tabular}{|c|c|c|c|c|c|c|c|}
\hline \multirow[b]{2}{*}{ Variables } & \multicolumn{3}{|c|}{ Total population } & \multicolumn{4}{|c|}{ Mild head injury subcategories } \\
\hline & $\begin{array}{l}\text { All HI } \\
n=67\end{array}$ & $\begin{array}{l}\text { Mild HI } \\
n=43\end{array}$ & $\begin{array}{l}\text { Moderate HI } \\
n=24\end{array}$ & $\begin{array}{l}\text { GCS } 13 \\
n=14\end{array}$ & $\begin{array}{l}\text { GCS } 14 \\
n=29\end{array}$ & $\begin{array}{l}\text { GCS } 14 \\
P T A>1 \\
n=16\end{array}$ & $\begin{array}{l}G C S 14 \\
P T A=1 \\
n=13\end{array}$ \\
\hline PTA (mean) & 7.8 & 5.5 & 12.0 & 5.0 & 5.7 & 9.6 & 1.0 \\
\hline RTW & $73 \%$ & $79 \%$ & $61 \%$ & $79 \%$ & $79 \%$ & $69 \%$ & $92 \%$ \\
\hline GOS (mean) & 7.1 & 7.3 & 6.9 & 7.1 & 7.3 & 7.1 & 7.6 \\
\hline DOS (mean) & 18.4 & 18.8 & 17.9 & 18.6 & 18.8 & 18.4 & 19.5 \\
\hline Complaints ${ }^{\star}$ & 4.8 & 4.6 & 5.3 & 4.9 & 4.4 & 5.3 & 3.2 \\
\hline \multicolumn{8}{|l|}{ GOSt: } \\
\hline 6 & $33 \%$ & $37 \%$ & $25 \%$ & $29 \%$ & $42 \%$ & $25 \%$ & $62 \%$ \\
\hline 7 & 49 & 51 & 46 & 57 & 48 & 56 & 38 \\
\hline 8 & 18 & 12 & 29 & 14 & 10 & 19 & - \\
\hline \multicolumn{8}{|l|}{ DOS: } \\
\hline 20 & $31 \%$ & $37 \%$ & $21 \%$ & $29 \%$ & $41 \%$ & $25 \%$ & $62 \%$ \\
\hline $17-19$ & 54 & 54 & 54 & 57 & 52 & 62 & 38 \\
\hline$<16$ & 15 & 9 & 25 & 14 & 7 & 13 & - \\
\hline
\end{tabular}

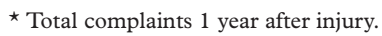

†Extended GOS. ${ }^{27}$

RTW=Return to work. duration of PTA was 7.8 days (SD 7.3, range 1-30 days). The mean GCS on admission was 12.6 (range 9-14). The sample comprised 24 patients who had sustained a moderate head injury and 43 patients who had sustained a mild head injury. Systemic injuries were seen in $27(40 \%)$ patients, mainly fractures of the limbs or facial fractures. The duration of the hospital stay varied from 1-58 days (mean 16 days). Most patients were discharged to their homes, eight patients $(12 \%)$ were transferred to a rehabilitation centre.

\section{COMPLAINTS}

One year after the accident most patients still had complaints related to the injury. Only nine patients reported no complaint at all (14\%). In 44 patients $(65 \%)$ two or more complaints were reported. The pattern of residual complaints varied between patients, but most frequent complaints were about disturbances in memory and concentration, fatigue, headache, and irritability (table 1). The highest reported incidence and severity of complaints was at first time of follow up, at 1 month after injury. Thereafter, the frequency of complaints decreased or stabilised over time although complaints about headache, irritability, neck pain, and anxiety increased slightly, especially 6 months after injury. No difference was found for the number and severity of complaints in mild or moderate head injury $(p>0.05)$. No correlation was found between residual complaints and age or education level.

\section{RETURN TO WORK}

One year after injury $73 \%$ of all patients were able to return to their previous jobs or study. Consequently one in four patients was able to resume previous activities only partially (score 1 ), or on a significantly lower level (score 2). None of the patients was disabled to such a degree that resumption of previous activities was not possible at all (score 3). Of those gainfully employed before the accident $(n=55)$, $67 \%$ resumed work and study or school was resumed in $91 \%$ of cases $(n=11)$. One student was not able to return to university 1 year after injury because of admission to a psychiatric ward for problems not related to the injury. Overall, the time between injury and resumption of previous activities was about 3 months (table 2). It seemed that although patients had resumed previous activities, either partially or completely, working on full capacity was possible only several months later, about 6 months after injury, mainly because of the complaints they experienced. Even the majority of patients $(81 \%)$ who resumed work completely had residual complaints. Patients resuming preinjury activities completely were slightly younger on average than those who did not resume such activities completely (31 and 41 respectively, $\mathrm{p}<0.05)$. No differences were found for education level or sex.

When comparing mild with moderate head injury, respectively $79 \%$ and $61 \%$ of patients resumed previous activities completely. Patients with a moderate head injury had a significantly longer time interval between injury and return 
Table 5 PTA and outcome. Outcome scores for different PTA durations (expressed in percentage of each PTA category)

\begin{tabular}{|c|c|c|c|c|c|c|c|}
\hline \multirow[b]{3}{*}{ PTA } & \multirow[b]{3}{*}{$n$} & \multicolumn{2}{|c|}{$\begin{array}{l}\text { GOS-5 } \\
\text { scale }\end{array}$} & \multicolumn{4}{|c|}{ GOS-8 scale } \\
\hline & & \multirow{2}{*}{$\begin{array}{l}G R \\
5\end{array}$} & \multirow{2}{*}{$\begin{array}{l}M D \\
4\end{array}$} & \multicolumn{2}{|c|}{$G R$} & \multicolumn{2}{|c|}{$M D$} \\
\hline & & & & 8 & 7 & 6 & 5 \\
\hline $1 \mathrm{~h}-1$ day & 15 & 100 & 0 & 60 & 40 & 0 & 0 \\
\hline $2-6$ days & 23 & 95 & 5 & 30 & 65 & 5 & 0 \\
\hline $7-14$ days & 14 & 71 & 29 & 28 & 43 & 29 & 0 \\
\hline$>14$ days & 15 & 53 & 47 & 13 & 40 & 40 & 7 \\
\hline
\end{tabular}

$\mathrm{GR}=$ Good recovery; $\mathrm{MD}=$ moderate disability.

to work than patients with mild head injury (4.1 and 2.7 months, $\mathrm{p}<0.05$, table 2 ).

OUTCOME CATEGORIES

Outcome as assessed by the GOS- 5 disclosed good outcome in $82 \%$ and moderate disability in $18 \%$ of patients 1 year after injury. When outcome was assessed by the (extended) GOS-8 optimal outcome (score 8 ) was found in $33 \%$ of patients only, whereas $49 \%$ of patients seemed to have mild complaints or disturbances not interfering with daily activities (score 7). As expected in this sample, none of the patients was severely disabled after 1 year. No differences in outcome categories were found for sex or type of injury. Outcome estimated by the differential outcome scale (DOS) showed a percentage of good outcome comparable with the GOS-8 (31\%), with 54\% of patients showing disturbances in one to three of the DOS subcategories and $15 \%$ of patients showing disturbances in all the DOS subcategories. With the application of the DOS scale more problems in several domains were noted (table 3). In general, cognitive and behavioural disturbances were seen in $40 \%$ and $48 \%$ of patients, and $37 \%$ of patients had physical disabilities. One in three of the patients with good recovery according to the GOS-5 had cognitive, behavioural, or physical problems with application of the DOS. The correlation between the GOS- 8 and the DOS was high $(r=0.87, \mathrm{p}<0.001)$. The intercorrelation between observers in determining outcome was good on both scales (weighted $\kappa 0.82$ for GOS-8 and 0.89 for DOS).

When comparing the outcome scores of patients with mild and moderate head injury, good recovery was seen in $88 \%$ and in $71 \%$ of the patients with moderate head injury. An optimal score according to the GOS- 8 was found in only one third of the patients. With application of the DOS scores, cognitive and behavioural problems seemed to be more prominent in the moderate head injury group (table 3 ).

Table 6 PTA and outcome. PTA duration for each outcome category (expressed in percentage of each outcome category)

\begin{tabular}{lllll}
\hline PTA duration & $\begin{array}{l}1 h-1 \text { day } \\
(n=15)\end{array}$ & $\begin{array}{l}2-6 \text { days } \\
(n=23)\end{array}$ & $\begin{array}{l}7-14 \text { days } \\
(n=14)\end{array}$ & $\begin{array}{l}>14 \text { days } \\
(n=15)\end{array}$ \\
\hline $\begin{array}{l}\text { Good recovery } \\
\text { Moderate disability }\end{array}$ & $\begin{array}{l}27 \% \\
0 \%\end{array}$ & $\begin{array}{l}40 \% \\
9 \%\end{array}$ & $\begin{array}{l}18 \% \\
33 \%\end{array}$ & $\begin{array}{l}15 \% \\
58 \%\end{array}$ \\
\hline
\end{tabular}

GCS AND PTA RELATED TO OUTCOME, RETURN TO WORK, AND COMPLAINTS

Outcome scores and return to work

When the outcome scores were correlated with the acute injury characteristics, no significant correlations were found between the outcome scores and the GCS at admission $(r=0.19$ and $r=0.23$ respectively). Analysis of the highest or lowest GCS obtained within 24 hours after injury also showed no correlation with the outcome.

A significant correlation was found for PTA with both outcome scales - that is, for the GOS-8 $(r=-0.46 \mathrm{p}<0.001)$ and the DOS $(r=-0.55 \mathrm{p}<0.001)$. This effect of PTA was even present in patients with a high GCS. Analysis of the patient group with GCS of 14 showed that within this group patients with a PTA of more than 1 day had considerably more complaints and lower percentage of return to work compared with those with a PTA of 1 day. In fact, this subgroup was comparable with moderate head injury (table 4 ).

When the outcome of patients was considered in relation to duration of PTA, it was found that a duration exceeding 14 days predicted a less favourable outcome-that is, moderate disability was seen with PTA duration of more than 7 days - and showed a clear increase, towards $50 \%$ of patients, when PTA duration was more than 14 days (table 5). Most patients with good recovery had PTA duration between 1 and 7 days and most patients with moderate disability had PTA duration exceeding 14 days (table 6).

A comparable pattern was seen when the relation of return to work with PTA and GCS was analysed. Patients who were not able to resume previous activities completely showed a significant longer duration of PTA compared with those who resumed work without problems (mean PTA 12.6 and 5.9 days, $\mathrm{p}<0.01$ ), but their GCS did not differ. The time interval between injury and return to work showed a significant correlation with PTA $(r=0.47$, $\mathrm{p}<0.01)$ but not with GCS scores $(r=-0.23$, NS) (figure).

\section{Complaints}

No correlation was found between the acute injury characteristics and the number of complaints or specific complaints at 1, 3, and 6 months and 1 year after injury.

\section{Multiple regression analysis}

Multiple regression analysis with stepwise regression disclosed two factors to be significant for determining the (extended) GOS: the PTA and the total number of complaints after injury. These complaints at 1 and 3 months after injury together with the PTA, explained $39 \%$ and $49 \%$ of the variance on outcome respectively. The total number of complaints seemed more important than separate complaints. Age, education level, and sex did not reach significance. With multiple regression analysis for the DOS the same factors were of influence in determining the outcome score, explaining $51 \%$ and $60 \%$ of the variance on the 

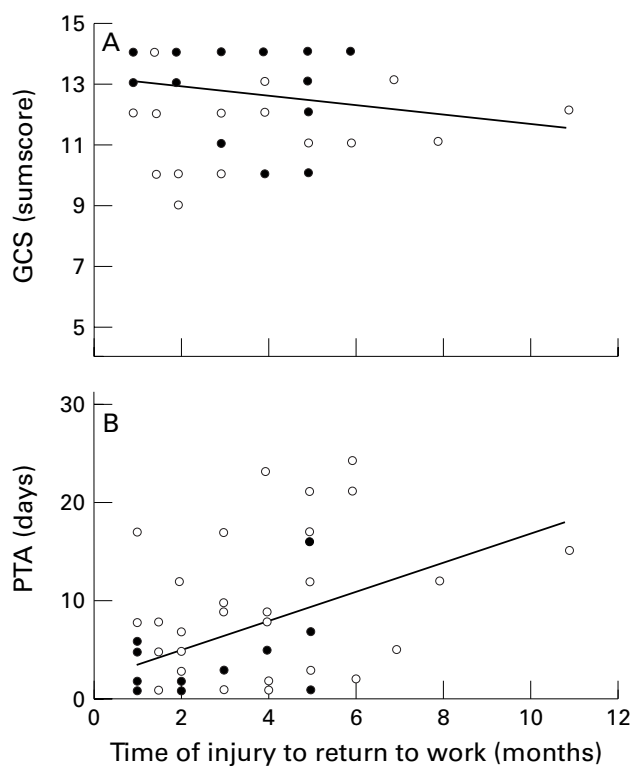

Time interval between injury and return to work related to Glasgow coma scale (GCS) (A) on admission and (B) post-traumatic amnesia (PTA). In the figures the regression lines are given. For PTA and time interval $r=0.47,(r$ $=0.22), p<0.01$ and for GCS and time interval $r=-0.23$ $\left(r^{2}=0.05\right), N S$. (Solid circles represent more than one value.)

outcome score 1 and 3 months after injury, respectively.

In multiple regression analysis with return to work as dependent factor the PTA and the number of complaints 3 months after injury were found to be significant for outcome in addition to cognitive problems, explaining $42 \%$ of the variance on the resumption of work. In this analysis the return to work scores 1 and 2 were taken together and scored as 1 . Although age reached significance in univariate analysis, this was not found in stepwise multiple regression. Other variables such as education level and sex did not account for more than $1 \%$ of the remaining variance, and none reached significance.

\section{Discussion}

In severe head injury, the GCS score and the duration of PTA are widely considered as reliable predictors of outcome. ${ }^{28}{ }^{29}$ Most studies described the GCS score as the most useful predictor of outcome. The few studies however, which studied the PTA as predictor of outcome, demonstrated a comparable predictive power of this variable. ${ }^{30-33}$ For cognitive outcome a higher prognostic value of the PTA compared with the GCS was encountered. ${ }^{34}{ }^{35}$ In minor head injury however, it is recognised that neither duration of PTA nor the GCS are useful measures of cerebral impact. ${ }^{36}$ The failure to predict outcome in this very mildly injured group of patients could be related to the relatively brief periods of unconsciousness and amnesia. In mild to moderate head injury, assessment of PTA is expected to be a better predictor of outcome than scores on the GCS. However, the studies on the value of PTA in determining outcome are not conclusive, mainly due to methodological problems and inconsistencies of the definitions used in various studies. ${ }^{48}{ }^{39}$ In most studies PTA has been determined retrospectively, which is less reliable in patients with short duration of PTA and with long time delay between assessments. ${ }^{40}$ Moreover, recollection of isolated events not representive for continuous memory could lead to false interpretation of the end of PTA, and are reported by about one third of patients with mild head injury. ${ }^{41}$

This study is one of the first in which PTA has been recorded prospectively in patients with mild to moderate head injury. The duration of PTA was found to be an important predictor of outcome whereas the GCS failed to predict outcome and return to work. The greater importance of PTA for outcome is also emphasised by the finding that a subgroup of patients with a relatively high GCS of 14 but with long duration of PTA, disclosed outcome scores comparable with moderate head injury patients. By contrast with other studies ${ }^{48}$ GCS was not found to be predictive of outcome. In these studies the PTA was derived from the GCS. Rimel et $a l^{\beta 8}$ analysed the GCS at discharge in relation to outcome, with one in four patients even discharged with a GCS of 14 or less. Consequently these patients were still in PTA. As stated earlier, ${ }^{1}$ a GCS of 14 or 13 reflects an optimal $\mathrm{M}$ score and suboptimal V and $\mathrm{E}$ scores. Because the V score in general reaches its maximum score later than the E score, it seems plausible that the outcome was determined by the $\mathrm{V}$ score and thus by the PTA instead of the GCS. In our study, the PTA was not derived from the GCS but determined by prospective daily assessment. Furthermore, even univariate analysis in our study showed no significant influence of the GCS on outcome. When looking at duration of PTA in relation to outcome a changing point between 7 and 14 days of PTA was found in line with other studies. ${ }^{33} 4243$ That is, moderate disability increased clearly after duration of PTA for more than 7 days with steep increase towards $50 \%$ of patients when PTA exceeded 14 days.

The outcome was determined by application of the GOS together with a more extensive outcome scale (DOS). The GOS is internationally used to determine outcome in severe head injury. ${ }^{26}$ This scale is a relatively simple one, assessing very general aspects of outcome more related to functional disability than to cognitive deficits. ${ }^{19}$ Patients sustaining a mild or moderate head injury are classified as having good outcome or moderate disability, although many patients have residual problems interfering with resumption of work or social activities, not specified by the original GOS. An extended version of the $\mathrm{GOS}^{27}$ has been recommended because this scale describes the upper range of outcome in more detail. It is suggested that even this extended scale lacks sensitivity reflected in the fact that patients improve insufficiently on the scale beyond 6 months, whereas clinical observation suggests the existence of improvement not reflected in the GOS.$^{44}$ For that reason we developed the DOS in which the outcome of the patient is characterised in several domains: neurophysical, cognitive, behavioural, and social impairments. In this study, we chose to determine the outcome at 1 year after injury. The reason is that residual 
sequelae may remain unrecognised until the patients resume work or social activities completely or at the moment when the support provided by family decreases. In general, problems of everyday life often only become clear several months after injury.

The outcome as determined in this study by the GOS showed a high percentage of good outcome $(82 \%) 1$ year after injury in accordance with other studies. ${ }^{15}$ However, when the extended GOS was applied, more than half of these apparently well recovered patients still had minor deficits or physical disabilities. None of the patients was severely disabled 1 year after injury. The application of a finely divided outcome scale (DOS) showed more details of outcome in patients. According to the DOS, cognitive and behavioural disturbances were seen in $40 \%$ and $48 \%$ of patients, and $37 \%$ of patients had physical disabilities. One in three of the patients with good recovery according to the original GOS had cognitive, behavioural, or physical problems with application of the DOS. Both the correlation between the extended GOS and the DOS and the interobserver correlation were high. This comparison between outcome scales warrants the conclusion that at least application of the extended GOS is necessary in this category of patients. The application of a more detailed outcome scale however, would give more information regarding the factors determining resumption of work or social activities.

In this study, 1 year after injury $73 \%$ of patients had resumed work or social activities while one in four patients was able to resume previous activities only partially, or on a lower level. In mild head injury, resumption of previous activities was possible in $79 \%$ of patients, comparable with results of other studies. ${ }^{1346}$ In moderate head injury $61 \%$ of patients resumed previous activities 1 year after injury. Rimel et $a b^{38}$ studied return to work 3 months after injury in moderate head injury and reported an unemployment rate of $69 \%$ compared with $55 \%$ in our study. The outcome of the study of Rimel et al is probably worse because of inclusion of more patients with alcohol misuse $(34 \%)$ and previous head trauma (42\%).

In the study of Dacey et $a l^{47}$ both brain and systemic injuries were found to contribute to outcome 1 month after injury. In our study 1 month after injury only $13 \%$ of patients with systemic injuries had resumed work compared with $34 \%$ of patients without systemic injuries. One year after injury, these percentages were $65 \%$ and $85 \%$ respectively. The frequency of physical disability however, as estimated with the DOS, was equal in both groups, although in the group with systemic injuries more behavioural and cognitive problems were noted. This suggests that return to work 1 year after injury is determined by cognitive problems and that physical problems are no more of importance. Moreover, although one in three patients were reported as having physical problems, most problems concerned cranial nerve dysfunction or post-traumatic epilepsy.

It is of importance to realise that most patients resumed work or study despite having com- plaints caused by the accident. One year after injury, only one in seven patients was completely free of complaints. In our study, most patients had resumed previous activities within 3 months after injury. However, most were not able to function directly at their preinjury level, mainly due to complaints they experienced. The most frequent complaints 1 month after injury were disturbance of memory and concentration, fatigue, noise intolerance, and dizziness. This is in agreement with other studies. ${ }^{48-50}$ As seen during follow up the frequency of complaints gradually decreased until 6 months after injury. From that time, complaints stabilised, although complaints of headache, irritability, and anxiety increased. This could suggest effects of external factors. The increase in these forementioned complaints seen after 6 months could be explained by the fact that patients by then had resumed previous activities completely. Minor disabilities regarding concentration or fatigue may remain unrecognised until the patient has resumed former activities completely.

With multiple regression analysis two factors were found to be important for outcome and return to work-PTA and the total number of complaints 3 months after injury. These two factors explained almost $50 \%$ of the variance on the outcome scores. Sex, age, and education level did not reach significance. Although age was found to be significant for return to work in univariate analysis, this was not found in relation to other factors as analysed in multiple regression. Further analysis has to show whether other factors are of influence in determining outcome in this category of patients. For example, it is to be expected that besides the PTA and complaints, diagnostic assessments such as CT or MRI and neuropsychological evaluation will further increase accuracy in predicting outcome in patients with severity of head injury covered by this study.

1 Rimel RW, Giordani B, Barth JT, et al. Disability caused by minor head injury. Neurosurgery 1981;9:221-8.

2 Barth JT, Macciocchi SN, Giordani B, et al. NeuropsychoBarth JT, Macciocchi SN, Giordani B, et al. Neuropsycho1983;13:529-33.

3 Englander J, Hall K, Stimpsons T, et al. Mild traumatic injury in an insured population: subjective complaints and return to employment. Brain Injury 1992;6:161-6.

4 Stambrook M, Moore AD, Peters LC, et al. Effects of mild, moderate and severe closed head injury on long-term vocational status. Brain Injury 1990;4:183-90.

5 Miller H. Accident neurosis. BMF 1961;1:992-8.

6 Lidvall HF, Linderoth B, Norlin B. Causes of the post-concussional syndrome. Acta Neurol Scand 1974;50: 3-144.

7 Gronwall D, Wrightson P. Cumulative effect of concussion. Lancet 1975; ;i: 995-7.

8 Kelly R. The post-traumatic syndrome: an iatrogenic disease. F Forensic Sci 1975;6:17-24.

Rutherford WH. Sequelae of concussion caused by minor head injuries. Lancet 1977;i:1-4.

10 Gennarelli TA, Thibault LE, Adams JH, et al. Diffuse axonal injury and traumatic coma in the primate. Ann Neurol injury and traumat

11 Povlishock JT, Becker DP, Cheng CLY, et al. Axonal change in minor head injury. $\mathcal{F}$ Neuropathol Exp Neurol 1983;42: 225-42.

12 Jane JA, Steward O, Gennarelli T. Axonal degeneration induced by experimental noninvasive minor head injury. $\mathcal{F}$ Neurosurg 1985;62:96-100.

13 Oppenheimer DR. Microscopic lesions in the brain following head injury. F Neurol Neurosurg Psychiatry 1968;31:299306.

14 Adams JH, Graham DI, Murray LS, et al. Diffuse axonal injury due to nonmissile head injury in humans: an analysis of 45 cases. Ann Neurol 1982;12:557-63.

15 Bullock R, Maxwell WL, Graham DI, et al. Glial swelling following human cerebral contusion: an ultra-structural following human cerebral contusion: an ultra-struct
study. $\mathcal{F}$ Neurol Neurosurg Psychiatry 1991;54:427-34.

16 Esselman PC, Uomoto JM. Classification of the spectrum of mild traumatic brain injury. Brain Injury 1995;9:417-24. 
17 Alexander MP. Mild traumatic brain injury: pathophysiology, natural history, and clinical management. Neurology 1995; 45:1253-60.

18 Russell WR, Smith A. Posttraumatic amnesia in closed head injury. Arch Neurol 1961;5:16-29.

19 Brooks DN, Hosie J, Bond MR, et al. Cognitive sequelae of severe head injury in relation to the Glasgow outcome scale. 7 Neurol Neurosurg Psychiatry 1986;49:549-53.

20 Gentilini M, Nichelli P, Schoenhuber R, et al. Neuropsychological evaluation of mild head injury. $\mathcal{F}$ Neurol Neurosurg Psychiatry 1985;48:137-40.

21 Levin HS, Mattis S, Ruff RM, et al. Neurobehavioral outcome following minor head injury: a three-centre study. f Neurosurg 1987;66:234-43.

22 Dikmen S, McLean A, Temkin NR. Neuropsychological outcome at one-month postinjury. Arch Phys Med Rehabi 1986;67:507-13.

23 Hugenholtz H, Stuss DT, Stethem LL, et al. How long does it take to recover from a mild concussion? Neurosurgery 1988;22:853-8.

24 Kibby MY, Long CJ. Minor head injury: attempts at clarifying the confusion. Brain Injury 1996;10:159-86.

25 McLean A, Dikmen S, Temkin N, et al. Psychosocial functioning at 1 month after injury. Neurosurgery 1984;14: 393-9.

26 Jennett B, Bond $M$. Assessment of outcome after severe brain damage. Lancet 1975; i:480-4.

27 Jennett B, Snoek J, Bond MR, et al. Disability after severe head injury: observations on the use of the Glasgow outcome scale. I Neurol Neurosurg Psychiatry 1981;44:285-93.

28 Choi SC, Muizelaar JP, Barnes TY, et al. Prediction tree for severely head-injured patients. F Neurosurg 1991;75:251-5.

29 Marshall LF, Gautille T, Klauber MR, et al. The outcome of severe closed head injury. F Neurosurg 1991;75:s28-37.

Appendix 1 University Hospital Groningen post-traumatic amnesia questionaire

\section{Patient name}

Date of injury

Date of PTA assessment

$\begin{array}{llll}\text { Morning } & \text { Afternoon } & \text { Morning } & \text { Afternoon } \\ \text { day } 1 & \text { day } 1 & \text { day } 2 & \text { day } 2\end{array}$

Personal data

1 Name your birthday

2 What is the year of your birth?

Orientation in place

3 What kind of building are you in now?

4 What place are you now?

5 Name reason of admittance

Orientation in time

6 Name present year

7 Name present month

8 Name present day

9 Name present tim

Memory of daily activities

10 What did you eat for breakfast?

11 Name recent visitors or an activity you

did this morning/afternoon

12 Do you remember my name?

Sumscore
30 Bishara SN, Partridge FM, Godfrey HPD, et al. Posttraumatic amnesia and Glasgow coma scale related to outcome in survivors in a consecutive series of patients with severe closed-head injury. Brain Injury 1992;6:373-80.

31 Ellenberg JH, Levin HS, Saydjari C. Posttraumatic amnesia as a predictor of outcome after severe closed head injury. Arch Neurol 1996;53:782-91.

32 Katz DI, Alexander MP. Traumatic brain injury. Predicting course of recovery and outcome for patients admitted to rehabilitation. Arch Neurol 1994;51:661-70.

33 Wilson JTL, Teasdale GM, Hadley DM, et al. Posttraumatic amnesia: still a valuable yardstick. $f$ Neurol Neurosurg Psychiatry 1993;56:198-201.

34 Brooks DN, Aughton ME, Bond MR, et al. Cognitive sequelae in relationship to early indices of severity of brain damage after severe blunt head injury. $\mathcal{F}$ Neurol Neurosurg Psychiatry 1980;43:529-34.

35 Karzmark P. Prediction of long-term cognitive outcome of brain injury with neuropsychological, severity of injury, and demographic data. Brain Injury 1992;6:213-17.

36 Middelboe T, Andersen HS, Birket-Smith M, et al. Minor head injury: impact on general health after 1 year. A prospective study. Acta Neurol Scand 1992;85:5-9.

37 Wrightson P, Gronwall D. Time of work and symptoms after minor head injury. Injury 1981;12:445-54.

38 Rimel RW, Giordani B, Barth JT, et al. Moderate head injury: completing the clinical spectrum of brain trauma. Neurosurgery 1982;11:344-51.

39 Tabaddor K, Mattis S, Zazula T. Cognitive sequelae and recovery course after moderate and severe head injury. Neurosurgery $1984 ; 14: 701-8$

40 King NS, Crawford S, Wenden FJ, et al. Measurement of post-traumatic amnesia: how reliable is it? $\mathcal{F}$ Neurol Neurosurg Psychiatry 1997;62:38-42.

41 Gronwall D, Wrightson P. Duration of post-traumatic amnesia after mild head injury. Fournal of Clinical Neuropsychiatry 1980;2:51-60.

42 Zomeren van AH, Burg van den W. Residual complaints of patients two years after severe head injury. $\mathcal{F}$ Neurol Neurosurg Psychiatry 1985;48:21-8.

43 Dikmen S, Temkin N, McLean A, et al. Memory and head injury severity. I Neurol Neurosurg Psychiatry 1987;50: 1613-18.

44 Anderson SI, Housley AM, Jones PA, et al. Glasgow outcome scale: an inter-rater reliability study. Brain Injury 1993;7:309-17.

45 Williams DH, Levin HS, Eisenberg HM. Mild head injury classification. Neurosurgery 1990;27:422-8.

46 Dikmen S, McLean A, Temkin N. Neuropsychological and psychosocial consequences of minor head injury. $f$ Neurol Neurosurg Psychiatry 1986;49:1227-32.

47 Dacey R, Dikmen S, Temkin N, et al. Relative effects of brain and non-brain injuries on neuropsychological and psychosocial outcome. F Trauma 1991;31:217-22.

48 McLean A, Dikmen S, Temkin NR. Psycosocial recovery after head injury. Arch Phys Med Rehabil 1993;74:1041-6.

49 King NS, Crawford S, Wenden FJ, et al. The Rivermead post concussion symptoms questionnaire: a measure of symptoms commonly experienced after head injury and its reliability. 7 Neurol 1995;242:587-92.

50 Minderhoud JM, Boelens MEM, Huizenga J, et al. Treatment of minor head injuries. Clin Neurol Neurosurg 1980;82:127-40.

Appendix 2 Differential outcome scale (DOS)

\begin{tabular}{|c|c|c|c|c|c|c|}
\hline Domain of outcome & 5 & 4 & 3 & 2 & 1 & Score \\
\hline $\begin{array}{l}\text { Neurophysical } \\
\text { Motor functions } \\
\text { Coordination } \\
\text { Sensibility } \\
\text { Cranial nerves } \\
\text { Ataxia } \\
\text { Epilepsy }\end{array}$ & $\begin{array}{l}\text { Complete recovery } \\
\text { (with minor } \\
\text { deficits) }\end{array}$ & $\begin{array}{l}\text { Mild impairment } \\
\text { limiting or hampering } \\
\text { daily life, work, or study }\end{array}$ & $\begin{array}{l}\text { Obvious impairment but } \\
\text { ADL independent }\end{array}$ & $\begin{array}{l}\text { Severe impairment } \\
\text { handicapped, ADL } \\
\text { dependent }\end{array}$ & PVS & \\
\hline $\begin{array}{l}\text { Cognitive } \\
\text { Memory } \\
\text { Slowness } \\
\text { Concentration } \\
\text { Flexibility } \\
\text { Overview } \\
\text { Fatiguability } \\
\text { Aphasia }\end{array}$ & $\begin{array}{l}\text { Complete recovery } \\
\text { or subjective } \\
\text { impairment only }\end{array}$ & $\begin{array}{l}\text { Mild impairment } \\
\text { limiting or hampering } \\
\text { daily life, work, or study }\end{array}$ & $\begin{array}{l}\text { Obvious impairment } \\
\text { strongly disrupting and } \\
\text { limiting daily life } \\
\text { functioning. Changes are } \\
\text { noted by laymen. }\end{array}$ & Severe impairment & PVS & \\
\hline $\begin{array}{l}\text { Personality/Behaviour } \\
\text { Irritability } \\
\text { (Verbal) disinhibition } \\
\text { Loss of initiative } \\
\text { Stress intolerance } \\
\text { Lack of affect } \\
\text { Childish behaviour } \\
\text { Anxiety/depression }\end{array}$ & $\begin{array}{l}\text { Complete recovery } \\
\text { or minor changes }\end{array}$ & $\begin{array}{l}\text { Mild changes, noted by } \\
\text { experts or by those who } \\
\text { knew patient before } \\
\text { injury }\end{array}$ & $\begin{array}{l}\text { Obvious changes, noted by } \\
\text { laymen who did not know } \\
\text { patient before injury }\end{array}$ & $\begin{array}{l}\text { Severe personality } \\
\text { changes }\end{array}$ & PVS & \\
\hline $\begin{array}{l}\text { Social } \\
\text { Work or study } \\
\text { Relations } \\
\text { Role pattern } \\
\text { Social contacts } \\
\text { Hobbies/leisure activities }\end{array}$ & $\begin{array}{l}\text { Complete } \\
\text { resumption of } \\
\text { former roles and } \\
\text { activities }\end{array}$ & $\begin{array}{l}\text { Work or study on lower } \\
\text { level; some loss of } \\
\text { contacts, hobbies, and } \\
\text { leisure activities }\end{array}$ & $\begin{array}{l}\text { Work in sheltered } \\
\text { environment, social isolation }\end{array}$ & $\begin{array}{l}\text { Work or study } \\
\text { impossible, social } \\
\text { isolation, coaching } \\
\text { necessary }\end{array}$ & PVS & \\
\hline
\end{tabular}

